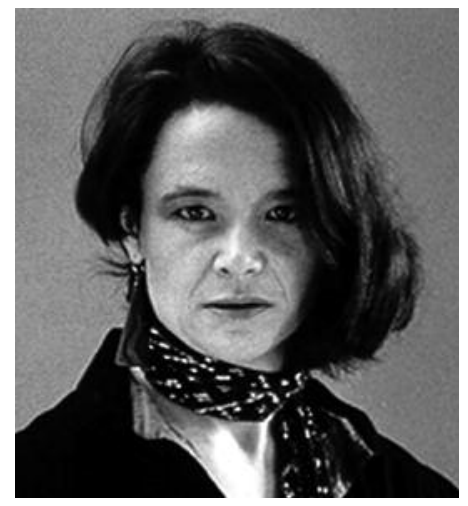

Anne Waldman (Milville, Nueva Jersey, 1945) es autora de cuarenta y dos libros, entre los que se incluye poesía, ensayo y antología. Hoy es reconocida como una de las voces más destacadas de la poesía contemporánea de EE.UU., fundamentalmente por el impulso que ha procurado a la poesía oral y por su magistral manejo del poema largo. Fundadora de la revista literaria Angel Hair, desde 1968 hasta 1978 fue directora del St. Mark's Poetry Project (asociación cultural por la que han transitado los autores más representativos de la poesía norteamericana de las últimas décadas). Junto a Allen Ginsberg fundó en 1974 la Jack Kerouac Disembodied School of Poetics, en Boulder (Colorado), emblemática institución que actualmente dirige. Entre sus poemarios cabe citar: On the Wing (1968), My Life! (1969), Baby Breakdown (1970), Goodies from Anne Waldman (1971), Spin Off (1972), The West Indies Poems (1972), Life Notes. Selected Poems (1973), Self Portrait (con Joe Brainard, 1973), Fast Speaking Woman (1974), Fast Speaking Woman and Other Chants (1975, reed. 1978), Sun the Blond Out (1975), Hotel Room (1976), Shaman (1977), Four Travels (con Reed Bye, 1979), Polar Ode (con Eileen Myles, 1979), To a Young Poet (1979), Countries (1980), Cabin (1981), First Baby Poems (1982), Makeup on Empty Space (1984), Invention (con dibujos de Susan Hall, 1985), Skin Meat Bones (1985), Blue Mosque (1987), The Romance Thing (1987), Helping the Dreamer: New and Selected Poems: 1966-1988 (1989), Not a Male Pseudonym (1990), Lokapala (1991), Fait Accompli (1992), Troubairitz (1993), Kill or Cure (1996), Fast Speaking Woman (1996), Marriage: A Sentence (2000), Vow to Poetry (2001), In The Room Of Never Grieve (2003), Structure Of The World Compared To A Bubble (2004), Outrider (2006). 


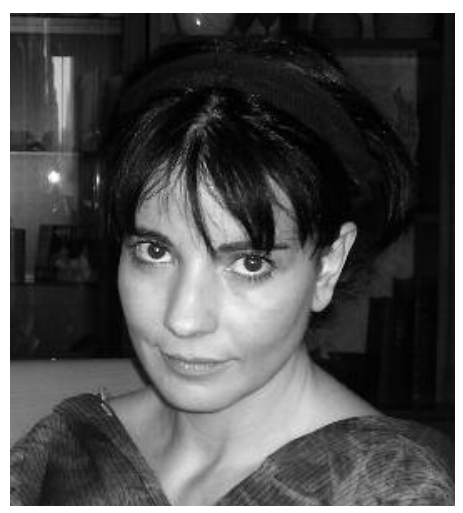

ISABEL CAMblor (Madrid, 1969) es licenciada en Filosofía y Letras y diplomada es Psicología. Ha colaborado con prensa y crítica literaria y ha publicado relatos y artículos en diversos medios desde 1998. Su primera novela, Perdona el desorden, fue reconocida por el jurado del premio Joven y Brillante; con Mistela con Aristóteles (Algaida, 2002) resultó finalista del IV Premio Río Manzanares. Su tercera novela, Maldita Cenicienta (Algaida, 2005), ha sido traducida al alemán, el rumano y el francés. Dios es una dama con moño, su cuarta novela, ha sido publicada por Planeta en 2008.

$\Rightarrow$ isabelcamblor@gmail.com 


\title{
ANNE WALDMAN (LA ELEGÍA)
}

ISABEL CAMBLOR

\begin{abstract}
RESUMEN
La noche del cinco de abril de 1997, el poeta Allen Ginsberg muere en brazos de la poeta Anne Waldman. Waldman logra capturar el espíritu beat durante unas horas, las necesarias para velar el cadáver. Su misión consiste en congregar uno por uno a cuantos poetas y demás criaturas líricas, vivas o muertas, sean capaces de producir una elegía beatnik en honor del poeta muerto. Anne Waldman impulsa la velada con su fuerza escénica de poeta y performer, y como anfitriona perfecta, se erige en guardiana del cuerpo de Ginsberg hasta la madrugada.

$\Rightarrow$ PALABRAS ClaVE: espíritu beat, elegía beatnik.
\end{abstract}

El año en que Allen Ginsberg murió

El cielo estaba roto de estrellas de metal

$\mathrm{Y}$ de gotas de mercurio, y de patinadores

Sobre la lámina del pozo.

(Amaral)

¡Haced que corra la voz! ¡Que los patrones se enteren!: ¡Allen Ginsberg ha muerto! Se quebró finalmente por despreciar la rima, por su frágil complexión de poeta maldito, por rasgar poemas y sobre todo por ser un villano orgulloso de serlo. La voz de la tribu ha desaparecido, amigos y enemigos, ciudadanos norteamericanos todos: se hace saber.

(Al otro lado del río Grande se halla la gran reserva de poetas que nombran y revelan, cantó Neruda, cantan ahora con menos fuerza los herederos de los dadaístas. 
Y poco a poco van sucumbiendo también, como estaba previsto que sucediera. Se advierte intensamente cómo los prudentes, los reverendos y los suspendidos en la posguerra desarticulan con facilidad parte del discurso; sin embargo, ahí escondidas resisten ciertas criaturas cómplices capaces de virar en redondo, criaturas de la noche que chillarán con todas sus fuerzas como murciélagos en la caverna de las ideas de academia para ahuyentar a los espíritus mansos.)

Anne Waldman, la poeta escénica que ruge en lugar de recitar, es perfectamente capaz hoy, el día de la muerte de Ginsberg, de tomar cartas en el asunto. Puntualicemos: ella es la única capaz.

Pero Anne Waldman no es sólo poeta, Anne es la fuerza misma de la naturaleza.

(Keith Taylor)

El cinco de abril de 1997 Anne Waldman tuvo el tiempo justo para correr hasta el lecho en el que su amigo agonizaba y recogerle en sus brazos. Ginsberg moría a la manera beat, con forma de verso libre: unos cuantos monjes budistas cantaban alrededor de su lecho en el mismo momento en que todo terminaba. Anne se colocó entonces justo detrás del cadáver caliente y, sin ruido, compuso un poema.

Hasta aquí todo es rigurosamente cierto, pero a partir de este momento en lo que yo cuente puede que haya escondida alguna patraña que me permitiré llamar pequeña licencia de autora. 
Estoy maquillando el espacio vacío

Todas las pátinas convergen en el espacio vacío.

Rubor sonrosado

En el espacio vacío.

(Anne Waldman)

Como un árbol centenario, Ginsberg ha muerto de pie. Sin embargo el Poeta ahora mismo yace tendido para poder ser velado con mayor facilidad.

Pero el mundo de trovadores desvergonzados se limita únicamente a observar el escorzo de su cuerpo muerto sobre el lecho, poco más pueden hacer, o poco creen que podría ya hacerse.

Sólo Anne Waldman está preparada para proceder; convoca a individuos de vocación iconoclasta, beat, anacorética y semiabatida -vivos y muertos-. Su intención es despedir a Allen Ginsberg (ese amigo rugiente que, como ella, aulló a la Guerra Fría con la misma náusea con que lo hacían los simbolistas franceses) como mandan los dioses.

Anne Waldman no usa carmín, ni rímel, sí usa rima, pero resulta imperceptible. Se alza por encima de las cabezas. Ella, la poeta y ventrílocua de Ginsberg, hembra y varón, guardiana de los bosques, reclama las presencias necesarias: ¡Acudid! ¡Acudid y preparaos para asistir a una velada fastuosa!

Remangaos las faldas señoras mías que vamos a atravesar el infierno.

(Williams Carlos Williams, prólogo a Aullido) 
Anne se envuelve en un extraño manto -una túnica de sacerdotisa pudiera ser-, y de esa guisa recita a César Vallejo en inglés. Esto lo hace hoy, pero hace diez años, cuando convocó al resto de plañideros, adoptó atuendo de poeta beatnik; cubierta de flores iba, como los cuerpos yertos destinados a instalarse en camposanto.

Vistió así porque las circunstancias lo exigían, porque se imponía la elegía al puro espíritu beat que acababa de morir.

Pero Anne no es, Anne nunca fue beat.

Hay que advertir que Anne Waldman no fue iniciada junto a los demás, aunque a ella esta particularidad le resulte indiferente, pero aun así hay que prevenir al lector.

Todo comenzó en la Six Gallery, en la costa oeste, cuando en el cincuenta y cinco Ginsberg dio el tono a todos los que se hicieron llamar después poetas de la generación beat. La lectura de Aullido marcó el nuevo ritmo. Y ella no estaba presente.

Perfectamente consciente de que no es una de ellos, se disfraza igualmente con flores y los selecciona con tanta sabiduría -y con tanto instinto- como si de uno de ellos se tratara.

Necesita el efecto erótico del escenario, es preciso, así que va invocándolos con una proposición cantada, más que recitada. Utiliza el criterio de la energía. Se concentra en los poemas hechos voz y diálogo, murmura entre dientes, pincha un vinilo donde las líneas de jazz dejan hueco para que todos esos versos hablados, gritados, penetren, y en medio de la cadencia libre, llena de la estricta con- 
ciencia de la nocturnidad, con su amigo todavía caliente en sus brazos, congrega a los poetas vagabundos que quieran entrar a ofrecer sus honores.

Anne ha escogido el café La Boheme, precisamente en San Francisco (porque tiene buen gusto y también por sentido de la legitimidad).

Para Charles Olson, La Boheme era puro fetiche. Charles Olson ha muerto, pero ésa no es razón suficiente para que no presida el adiós junto a ella. Además no hay que olvidar que Anne y Olson componen sobre un tándem. Ninguno de los dos es beat, ni confesional, ambos se establecen en un ángulo muerto y libre, pasan desapercibidos, se muestran instantáneos, como el poema hablado. Por todas estas razones -y también por buen gusto y sentido de la legitimidad-, Olson despierta para acompañarla esta noche, luego volverá a dormir probablemente para siempre.

Con el decimonoveno compás entra el segundo invitado. Podría haber tensión, pero no se da el caso. Lawrence Ferlinghetti se muestra altivo ante el mundo: haber editado a Camus proporciona demasiado prestigio como para fingir modestia. Anne Waldman responde con altivez a la altivez de Ferlinghetti, ella editó al mismo Ginsberg, no va ella a ser alfombra de nadie justo ahora, no es posible mayor credencial, dadas las circunstancias.

Ferlinghetti y Anne se entienden, aun en versión fanfarrona se entienden. Son performers, y no todo el mundo puede ser performer por muy beatnik que uno sea. Eso une, proporciona afinidad y la complicidad que en esta noche de elegía se exige. 
Michael Mc Clure entra con paso firme. Podría permitirse ser arrogante igualmente, es uno de los cinco que participaron en la lectura de Six Gallery. Y eso son palabras mayores. Trae debajo del brazo «Point lobs: animism» y toca la armónica porque necesita jolgorio hasta en los funerales. Detrás de él Janis Joplin reza a su manera: pide a Dios que le regale un Mercedes Benz y que pague la siguiente ronda; de estos dos podría decirse también que conducen un tándem.

Se hace el silencio. Entra Burroughs. El guardia de seguridad se pone algo tenso: el nuevo invitado lleva un rifle en la mano izquierda y blande su carné de la Asociación Nacional de Armas en la mano derecha. Anne y Olson lo aceptan, un ligero gesto de sus cabezas y el guardia no mueve una pestaña. Nadie puede interceptar el paso de Burroughs. Es Burroughs, sin él las cosas no habrían evolucionado. Además dentro de dos meses morirá también, seamos pues indulgentes.

A pesar de ser un adicto al wellness y a la medicina antiedad, Olson vaticina que en agosto Burroughs alcanzará otra vida no sabría especificar si mejor o peor (pero por ser el más maldito de todos los poetas beat, tal vez tenga el privilegio de encontrarse en el Hades con Rimbaud, trata de templar Olson aunque sea un poco su presagio terrible). Burroughs llora un rato al escuchar las nuevas y luego regresa al bosque de boj donde vive, esnifa coenzima Q10 y grita que Howl es y será por siempre el único himno. En eso tiene razón, y desde la fiesta, nadie se arrepiente por haberle dejado entrar.

Muriel Rukeyser guiña un ojo a los concurrentes, pasa delante de Anne, es la anfitriona, por lo que le parece de recibo soplarle al oído: 
«No más máscaras! ¡No más mitología!». Anne sonríe ante la primera observación pero parece impacientarse algo ante la segunda.

Entra Robert Bly muy enfadado y provoca a Olson: ¿Qué hiciste tú cuando Vietnam? Sólo llorar. En cuanto a ti (ahora se dirige a Anne), tú no es que mires las profundidades del inconsciente, aunque te las das de hacerlo atentamente (busca el pareado aposta), tú miras las profundidades de tu propio ombligo.

Nadie le hace caso, son cosas que pasan. Siempre se han peleado entre ellos. No sólo batallan académicos frente a experimentales, eso sería muy previsible. Adoran pelear -sólo los de la escuela de Nueva York podrían ser considerados conciliadores-, alaban el desencuentro.

(Tal vez pelear sea un principio dadaísta, sugiere O’Hara).

Alguien dice: «Por supuesto, amigos, "EL CHORRO DE SANGRE ES POESÍA"». Es Sylvia Plath, que exige ser invitada y, como hada perversa, amenaza con dormirlos a todos a punta de aguja de huso si le impiden pasar. Olson la rechazaría, por suicida. Pero en esta fiesta de vivos y muertos ¿quién se aventura a disponer el modo en el que alguien debe morir? ¿Es más digna acaso una Muerte que intercepta a la vida sin que nadie la haya reclamado? ¡Qué insolencia! El suicidio, amigos vivos y muertos, es el summum de la pasión, y la pasión siempre es bienvenida en una elegía.

Entre pues Sylvia Plath. 
Y junto a ella Adrianne Rich. Todos se arrodillan entonces, más ellas que ellos, creo en la diosa madre, todopoderosa, creo en Adrianne capaz de inventar un lenguaje con tal de rechazar el lenguaje patriarcal. Las chicas sonríen. Los chicos desvían la atención y piden una oración por las almas de los simbolistas franceses, que en paz descansen.

Hilda Doolittle y William Carlos Williams, canonizados, observan, bendicen como mucho, desde su paraíso iconoclasta. Por encima de ellos, sólo Eliot, aburrido, ocioso, trata de acercarse al Hades, donde reinan Baudelaire y su prostituta desdentada y Rimbaud, que se empeña en gritar Merde! (aquí, en el paraíso de Belcebú, están muy bien vistas las blasfemias).

Los muertos se retiran finalmente (ya antes trataron de retirarse de la Historia, pero no les resultó tan sencillo).

Llegan templados poetas de los años cincuenta, burócratas literarios, tratan de colarse, pero alguien les descubre rezando un padrenuestro por Eliot, y eso sí que no.

Burroughs regresa del bosque de boj, canta acompañado de la música de Ray Manzarek, antiguo teclista de The Doors, y eso da mucho juego y mucho prestigio en la pequeña fiesta funeraria. (Qué bien se sentiría aquí Bukowski, se atreve a pensar Anne. Es también un muerto reciente, y se sentiría cómodo viendo cómo nos herimos los unos a los otros. Todo resulta tan felizmente inarmónico... pero nos ha hecho el feo de no aparecer, él sabrá.) 
Por fin, Ken Kesey, el invitado de honor. Llega tarde y aparece sobre un nido de cucos y se trae consigo a Milos Forman (todos aplauden) y también a la señorita Rachet, a Frederickson, al Jefe, a Manzini (que se queja de fatiga crónica), a Mc Murphy y a Taber. El Jefe lleva una almohada en la mano y su mirada torva se clava en la cicatriz de Mc Murphy, recién lobotomizado. Llega Paul McCartney a calmar los ánimos. Se trae el logotipo de Apple. Kesey grabó ahí, en Apple. Todos los personajes guardan silencio y reverencian a McCartney, que es gentil y aporta su granito de arena beatnik mostrando imágenes del Sargento Pimienta.

Burroughs está solo. Anne se compadece y hace traer a Bowie (es el único al que nunca percibe hostil). Bob Dylan se dirige hacia un reservado con la anfitriona, una mujer, la gran mujer que habla rápido, y que, sola junto a él, se rompe como una niña seducida. Se besan mientras Iggy Pop canta junto a Bowie «Vi a las mejores mentes de mi generación enloquecer» y Patti Smith anima el cotarro con sus aullidos perfectos: «Go Ginsber, go». Todos aplauden nuevamente. Sólo Frank Zappa se burla de Ginsberg y de su forma de recitar en vida -circunstancia que enfurece moderadamente a Anne-.

Pronto asomará el sol. Se iza lentamente la raya del alba pero sólo los vivos obtendrán sus favores. Llega el momento de la nostalgia (ésta también para difuntos receptivos). Anne decide recitar todo lo que cada uno de ellos vaya recordando. Pide un Brainstorming.

Roger Waters y el resto de pinkfloydistas estrenan la lluvia de ideas: recuerdan en verso el encuentro en el Royal Albert Hall. Pero no gusta el sonido de sus guitarras sinfónicas y les silban. 
Entra Miles, el dueño de la librería Indica. Es el autor de la gran biografía de Ginsberg, por lo que todos le reverencian y piden testimonio. Sólo Paul Mc Cartney tiene sus reservas (no le parece justo que el dueño del antro donde Lennon y su grotesca japonesa con pretensiones experimentales se conocieron, ande ahí, tan campante, impune, recitando recuerdos que indiscutiblemente son patrimonio de todos). El ambiente parece inesperadamente tornarse algo tenso y Anne no duda, con rápidos reflejos, en recurrir a sus propias evocaciones para suavizar. Localiza un capítulo que es preciso hacer notar: ella fundó junto a Ginsberg la Escuela de Poetas Kerouac. O tempora, o mores. Ojalá estuviera aquí Kerouac el grande, pero no, es el único muerto que no escucha ouijas, no acaba de perdonar que Ginsberg jurara haber tenido sexo con él (curioso es observar que Burroughs parece no tener nada que objetar, aunque fuera acusado exactamente de lo mismo).

Alguien trata de que Dylan convenza a Kerouac, pero no es sencillo. Salta con un alegato que carece de réplica posible:

-Cuando estuvimos juntos, Ginsberg y yo, cantando frente a su tumba (la de Kerouac, me refiero) en el cementerio de Lowell Edison, entre lápidas y cipreses, se oyó claramente un exabrupto: «iA callar y a dejar descansar a las almas inmortales de los poetas mortales!» (Asiente Anne: «Cierto, cierto, fue escalofriante. NO insistamos, amigos».)

Anne Waldman no podría permitir que decayese la fiesta, todo performer es en esencia un animador sociocultural y es su deber dar nuevo impulso cuando flaquean los ánimos. Sólo por esta vez llega 
a un acuerdo con su propia energía masculina y cruza su cuerpo a tal velocidad que nadie lo advierte. Así está en idóneas condiciones para recitar First baby poems. Y lo hace para albricias de la concurrencia. Y así es como en una circunstancia impecable permite Anne Waldman que regrese el espíritu del verano de San Francisco.

Los representantes de la comunidad afroamericana proponen un solo de bajo y teclado midi para acompañar a Anne. Sin duda tenían buenas intenciones, pero Dylan les hace callar, Anne llena completamente con su voz. Y ella prolonga sus versos hermafroditas haciendo las delicias de Ginsberg, muerto, y cantando un collage a la fecundidad. Finalmente aparece el arpegio de notas graves, ha sido inevitable, una línea comprometida de contrabajo impone un contrapunto en cada sílaba:

Oh estratégico mapa del desastre, hambrienta América

Blanco del canto, del poema que anda a los tumbos, de toda la protesta Una larga e imperfecta historia ensombrece tu rostro América: deja que el sufrimiento, la fatiga, el sexo y las distracciones sublimes caigan en el olvido se desvanezcan de los expedientes Dale tu permiso a este mundo para que pueda seguir Respirando

Amanece por fin. 